\title{
Validation of Catenary-based Methods for Cable Road Layout Planning ${ }^{\dagger}$
}

\author{
Leo Gallus Bont *, Laura Ramstein *, Fritz Frutig and Janine Schweier
}

Citation: Bont, L. G.; Ramstein, L.; Frutig, F.; Schweier, J. Validation of Catenary Based Methods for Cable Road Layout Planning. Environ. Sci. Proc. 2021, 3, 102. https://doi.org/ 10.3390/IECF2020-07775

Academic Editors: Angela Lo Monaco, Cate Macinnis-Ng and Om P. Rajora

Published: 10 November 2020

Publisher's Note: MDPI stays neutral with regard to jurisdictional claims in published maps and institutional affiliations.

Copyright: $(2020$ by the authors. Licensee MDPI, Basel, Switzerland. This article is an open access article distributed under the terms and conditions of the Creative Commons Attribution (CC BY) license (http://creativecommons.org/licenses/by/4.0/).
Swiss Federal Institute for Forest, Snow and Landscape Research (WSL), Sustainable Forestry Group, Zuercherstrasse 111, CH 8903 Birmensdorf, Switzerland; friedrich.frutig@wsl.ch (F.F.); janine.schweier@wsl.ch (J.S.)

* Correspondence: leo.bont@wsl.ch (L.B.); laura.ramstein@wsl.ch (L.R.)

+ Presented at the 1st International Electronic Conference on Forests - Forests for a Better Future: Sustainability, Innovation, Interdisciplinarity, 15-30 Novermber 2020; Availvable online: https://iecf2020.sciforum.net.

\begin{abstract}
Cable-based technologies have been a backbone for harvesting on steep slopes. Computing the layout of a single cable road requires considering the standards of structural design, aiming to (1) guarantee structural safety, and (2) provide the required serviceability. Currently applied analysis methods, such as the Pestal method, are unprecise. Alternatively, methods based on the catenary, such as Zweifel or Irvine, are better suited to analyze and predict load path and occurring forces for skylines anchored fix on both ends. However, studies that validate those catenary analyses (concurrently load path and forces) are rare and were not carried out under realistic heavy load conditions. Therefore, the aim of the project was to validate the catenary analyses under realistic, heavy load conditions for cable roads with multiple spans. In two case studies in Switzerland, the deflection in every span as well as the skyline tensile force at the anchor were measured for different load configurations and compared with theoretical computations of Zweifel and Pestal. The approach of Zweifel maps the mechanical properties realistic. However, as proven by our measurements, it slightly overestimated the deflection and the skyline tensile forces because the friction on the supports was neglected (between skyline and saddle). The deflections calculated with the Pestal formulas were significantly larger than the measured values, in particular with heavy load and in large spans. Our measurement studies confirmed that the mechanical properties of a cable road can be described adequately with the algorithm by Zweifel. However, it should be further developed with the inclusion of effects like the friction to improve the efficiency, safety and cost-performance ratio in cable road planning.
\end{abstract}

Keywords: cable road layout; catenary based methods; deflection; skyline tensile force; forest management planning

Supplementary Materials: The following are available online at www.mdpi.com/26734931/3/1/102/s1.

Data Availability Statement: The data presented in this study are available on request from the corresponding author. 